\title{
Aseptically processed and chemically sterilized BTB allografts for anterior cruciate ligament reconstruction: a prospective randomized study
}

\author{
Peter A. Indelicato • Michael G. Ciccotti • \\ Joel Boyd • Laurence D. Higgins • Benjamin S. Shaffer • \\ C. Thomas Vangsness Jr.
}

Received: 28 February 2012/ Accepted: 19 November 2012/Published online: 1 December 2012

(C) The Author(s) 2012. This article is published with open access at Springerlink.com

\begin{abstract}
Purpose To compare the clinical outcomes of bonepatellar tendon-bone (BTB) allografts processed via a novel sterilization system with the traditional aseptically processed BTB allografts for anterior cruciate ligament (ACL) reconstruction.

Methods A total of 67 patients undergoing ACL reconstruction at 6 independent investigation sites were randomized into one of two intervention groups, BioCleanse-sterilized or aseptic BTB allografts. Inclusion criteria included an acute, isolated, unilateral ACL tear, and exclusion criteria included prior ACL injury, multiligament reconstruction, and signs of degenerative joint disease. Post-op examiners and patients were blinded to
\end{abstract}

\footnotetext{
P. A. Indelicato $(\square)$

Department of Orthopaedics and Rehabilitation, University of Florida, 3450 Hull Road, Gainesville, FL 32607, USA

e-mail: indelpa@ortho.ufl.edu

M. G. Ciccotti

Rothman Institute, Department of Orthopaedic Surgery,

Thomas Jefferson University, Philadelphia, PA, USA

J. Boyd

TRIA Orthopaedic Center, Minneapolis, MN, USA

L. D. Higgins

Department of Orthopedic Surgery, Brigham and Women's Hospital-Ortho, Boston, MA, USA

B. S. Shaffer

Washington Orthopaedic and Sports Surgery Center, Clinical

Orthopedics, George Washington University,

Washington, DC, USA

C. T. Vangsness Jr.

Department of Orthopaedic Surgery, University of Southern California, Los Angeles, CA, USA
}

graft type. Patients were evaluated at 6, 12, and 24 months. Clinical outcomes were compared using the IKDC, a KT-1000 knee arthrometer, level of effusion, and ranges of motion (ROM).

Results After randomization, 24 patients received aseptic BTB allografts and 43 patients received BioCleanse-sterilized allografts. Significant improvement in IKDC scores $(P<0.0001)$ as well as KT-1000 results $(P<0.0001)$ was noted over the 24-month period for both groups. IKDC or KT-1000 results were not significantly different between groups at any time point. Active flexion ROM significantly improved from pre-op to 24-month follow-up $(P<0.0001)$ with no difference between groups at any time point. Active extension ROM did not differ significantly between the two groups.

Conclusions These results indicate that the sterilization process, BioCleanse, did not demonstrate a statistical difference in clinical outcomes for the BTB allograft at 2 years. The BioCleanse process may provide surgeons with allografts clinically similar to aseptically processed allograft tissue with the benefit of addressing donor-torecipient disease.

Level of evidence II.

Keywords Anterior cruciate - Allograft - Sterilized . Outcomes · IKDC

\section{Introduction}

In anterior cruciate ligament (ACL) reconstruction, the choice of graft has been an area of debate for several years. While there are arguments made that autograft is the gold standard $[6,40]$, the use of allografts is relatively common with successful outcomes having been well documented in 
the literature. The use of allograft tissue has been noted to decrease operating time, eliminate donor site morbidity, and increase the tissue available for multi-ligament cases $[24,42]$. Clinical studies that evaluated outcomes reported positive results for chronic ligamentous laxity [23]. Subsequently, there have been a number of reports of successful outcomes using allografts in surgery $[7,15,16]$. Further support for the use of allografts can be seen in long-term studies which have reported positive results for patients as long as 10 years after surgery [1, 20, 23]. With the prospect of increased morbidity associated with autograft procedures [2, 12, 43], the rationale for allograft use in ACL surgery seems warranted.

One disadvantage which has received a great deal of attention is that disease can be transmitted as a result of the allograft. Use of allograft tissue has historically been associated with HIV and HCV transmission along with bacterial infections, resulting in significant morbidity and mortality [5]. These risks can be minimized by rigorous donor screening, aseptic harvesting techniques, and tissue processing, but the allograft that is only aseptically processed cannot be guaranteed to be free of all viruses or bacterial spores.

Historically, multiple sterilization techniques have been used for allograft tissue, most notably gamma irradiation and ethylene oxide. The use of gamma irradiation and ethylene oxide has decreased over time in favour of less destructive and biologically friendly chemical cleaning processes [18, 26, 27, 30, 36, 38, 39, 42].

The BioCleanse ${ }^{\circledR}$ tissue sterilization process (RTI Biologics, Alachua, FL) is a non-thermal combination of mechanical and chemical processes that has been reported to inactivate or remove all sources of infectious disease transmission while not compromising the biomechanical and physiological properties of allograft bone and soft tissue $[21,22,29,34]$. To date, there has not been a direct comparison of clinical outcomes via a randomized, prospective clinical trial with this type of sterilized allograft.

The purpose of this study was to compare the clinical outcomes of patients who underwent ACL reconstruction with BioCleanse BTB allografts to those who received the traditional aseptically, non-irradiated processed BTB allografts. It was hypothesized that patients undergoing ACL reconstruction with BioCleanse BTB allografts would not have statistically or clinically meaningful differences in outcomes from patients who received non-irradiated aseptically processed BTB allografts.

\section{Materials and methods}

Patients who presented with an acute ( $<4$ months), isolated ACL rupture were asked to participate in this study. The patients were at one of 6 independent research sites. A total of 67 patients were randomly assigned, to 1 of 2 groups using the ranblock.exe application, and received either the BioCleanse or aseptic BTB allograft. The mean age of all patients was 34 (SD 9) years. Patients requiring multiligament reconstruction, moderate to severe concomitant meniscal repair or ACL revision surgery were excluded. This study was approved by the Institutional Review Board (or equivalent) at all the participating sites and all subjects gave informed consent.

Aseptic grafts were obtained from one of 3 tissue banks currently providing BTB allografts in the United States. All donors were screened, and all tissues were harvested and processed according to standards set forth by the American Association of Tissue Banks [3]. Each investigational site chose their own supplier for the aseptic grafts.

The BioCleanse tissue sterilization system uses a combination of mechanical and chemical processes, working in conjunction with each other. The mechanical component applies oscillating positive and negative pressure in the presence of the chemical agents (including detergents and sterilants), which perfuse the tissue. This combination removes blood and lipids and inactivates or removes pathogenic microorganisms. Repeated rinses throughout the process remove debris, and final rinses remove residual chemicals, leaving the tissue biocompatible [42].

All patients underwent single incision arthroscopic ACL reconstruction under general anaesthesia. A tourniquet was used in every case. All articular damage was noted and recorded using the Outer-bridge classification system. In addition, all meniscal damage was identified, and lesions were treated with partial menisectomy. Following this, a guide system was used that placed the tibial tunnel centre at the anatomical centre of the native ACL. The femoral tunnel was drilled just anterior to the over the top position at the ' $2 \mathrm{AM} / 10 \mathrm{PM}$ ' isometric single bundle location using the standard transtibial approach. An endoscopic femoral aimer was used to minimize patient to patient variability. The grafts were reconstituted using room temperature saline for a minimum of $10 \mathrm{~min}$. The BioCleanse grafts were preshaped with a $10 \mathrm{~mm}$ diameter and $25-30 \mathrm{~mm}$ length bone blocks. The aseptic grafts were shaped individually in each centre during surgery to the same dimensions as the BioCleanse preshaped grafts. The graft was then pulled distal to proximal via the tibial tunnels. Both femoral and tibial fixations were achieved using metallic interference screws. After fixation at the femur, the graft was tensioned with approximately $20 \mathrm{lbs}$ of force for tibial fixation at near extension. Following this, the knee was put through a full range of motion to verify that there was no graft impingement. Stability was then checked to make sure that both the anterior drawer sign and the pivot shift were eliminated. At this point, the arthroscopic instruments were 
removed and the distal tibial incision was closed in a standard fashion.

All patients followed a uniform ACL rehabilitation protocol. Following surgery, the patients began a therapistdirected physical therapy programme. Post-operative rehabilitation programmes emphasized range of motion restoration, quadriceps strengthening, and patellofemoral joint protection. These were divided into 6 phases using objective criteria for advancement to the next phase; these phases took up to 6 months to complete.

At 3, 6, 12, and 24 months post-operatively, the patients returned to their respective clinics for an evaluation including the International Knee Documentation Committee (IKDC) form along with a physical examination for range of motion (ROM) effusion and a KT-1000 knee arthrometer test. All sites received a training DVD demonstrating KT-1000 testing to ensure standard and consistent use when evaluating the ACL at maximum manual testing. Previous research has shown KT-1000 testing to be reliable and repeatable $[14,25,28]$. Both the examiner and the patient were blinded as to the type of graft implanted.

\section{Statistical analysis}

The IKDC scores, KT-1000 measures, and ROM were compared using a repeated-measures ANOVA. A chisquare test and Fisher's exact test were used to compare between categorical variables, that is, gender distribution and grade of effusion. Demographic characteristics were compared using a Student's $t$ test. An a priori power analysis was primarily based on KT-1000 measures. Using G3 software (Heinrich Heine University Düsseldorf, Germany) with an effect size of 0.33 , alpha of 0.05 , power of 0.80 , for 3 groups (aseptic, gamma-irradiated, and BioCleanse grafts), we estimated that 112 patients would be required. Due to circumstances such as surgeon preference and patient recruitment, the gamma-irradiated BTB allograft group was dropped. This left the aseptic and BioCleanse grafts for the final analysis. The initial statistical plan had been an unbalanced design, allowing for an unequal number of patients in each group. The level of significance for all statistical tests was set at an alpha level of 0.05 .

\section{Results}

As shown in Table 1, there was no significant difference between the groups for age, body mass index, or gender distribution. Of the 43 patients enrolled in the BioCleanse group, there were 29, 24, 20, and 18 tested at 3, 6, 12, and 24 months, respectively. For the aseptic group, testing was completed on $23,20,13$, and 10 patients at 3, 6, 12, and 24 months, respectively.
Table 1 Descriptive data for the patients in this study

\begin{tabular}{llll}
\hline & $\begin{array}{l}\text { Aseptic } \\
\text { allografts }\end{array}$ & $\begin{array}{l}\text { Sterilized } \\
\text { allografts }\end{array}$ & $P$ value \\
\hline Age (years) & $31.3 \pm 9.2$ & $35.6 \pm 8.9$ & $\mathrm{~ns}$ \\
Body mass index & $26.7 \pm 4.8$ & $26.8 \pm 4.7$ & $\mathrm{~ns}$ \\
Revision surgeries & 1 & 1 & $\mathrm{~ns}$ \\
Male $(n)$ & 16 & 25 & $\mathrm{~ns}$ \\
Female $(n)$ & 8 & 18 & \\
\hline
\end{tabular}

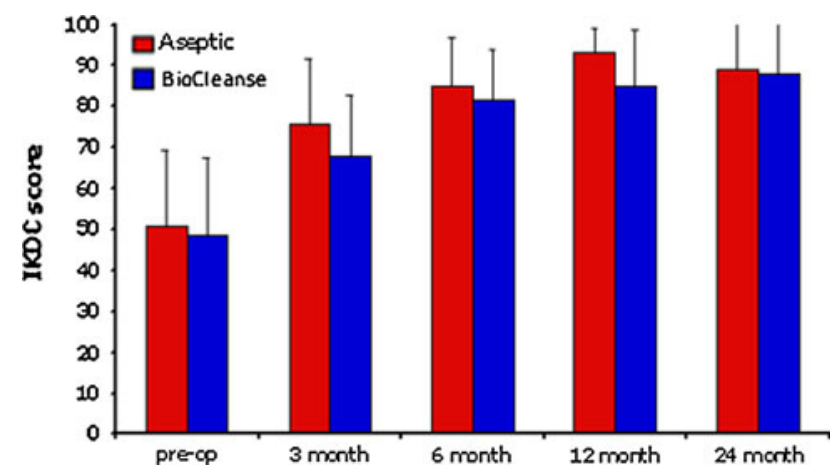

Fig. 1 The IKDC scores for the 2 groups. There were no statistically significant differences between the 2 groups at any time point

The data for IKDC scores are presented in Fig. 1. The mean IKDC pre-operatively was 51 (95\% CI 42.3-53.8) and 48 (95\% CI 42.3-53.8) for the aseptic and BioCleanse groups, respectively. This improved over the 24 months to 89 (95\% CI 81.2-96.4) for the aseptic group and $88(95 \%$ CI 80.6-95.4) for the BioCleanse group. There was no statistically significant difference in IKDC scores at any time point measured.

Similarly, the KT-1000 measurements steadily improved over time, from a mean of $4.6 \mathrm{~mm}$ (95\% CI 3.7-6.1) and $4.3 \mathrm{~mm}$ (95\% CI 3.3-5.3) for the aseptic and BioCleanse groups, respectively. At the end of the study, the anterior knee displacement as measured by the KT-1000 was recorded at $1.6 \mathrm{~mm}(95 \% \mathrm{CI} 1.1-2.1)$ and $1.5 \mathrm{~mm}(95 \%$ CI 0.9-2.1) for aseptic and BioCleanse groups, respectively (Fig. 2). No statistically significant difference in KT-1000 scores was found between the groups at any time point.

The results for range of motion (ROM) showed no significant differences between groups at any time point. This was true for the active flexion ROM (Fig. 3) as well as the deficit for passive extension, measured between ipsilateral and contralateral legs. Effusion grading showed no significant differences between the groups. There were no complications noted at 24 months.

There were no cases of either disease transmission or infection that could be attributed to the grafts. This was true for both aseptic and BioCleanse grafts. 


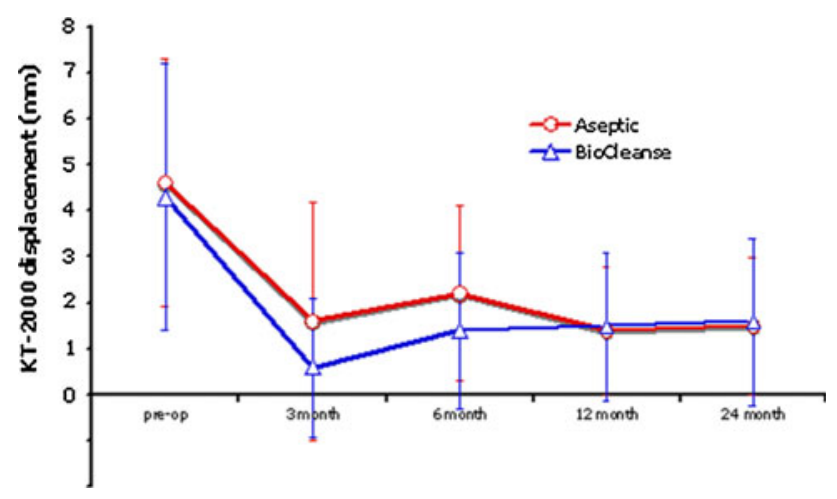

Fig. 2 The mean KT-1000 side-to-side differences for anterior displacement at four time points. No significant differences were found between groups

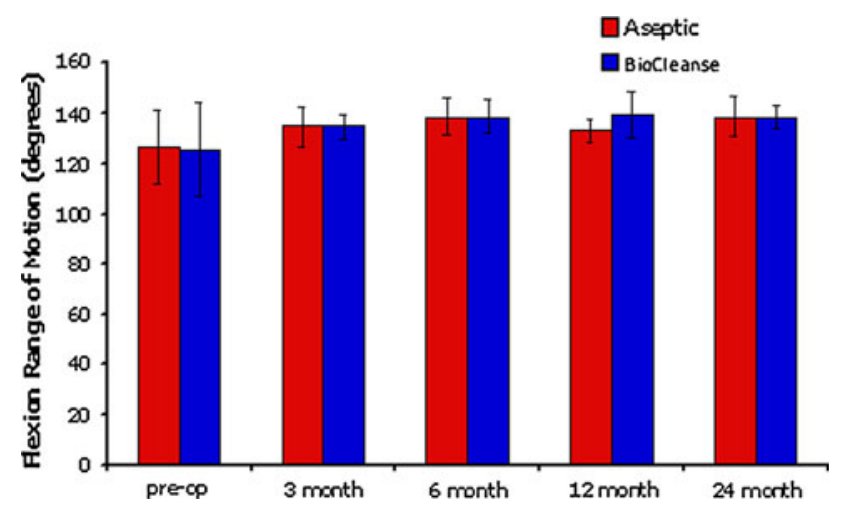

Fig. 3 Mean active flexion range of motion for the treated knee for both groups

\section{Discussion}

This prospectively evaluated clinical outcomes study compared aseptically processed allografts to those treated through the BioCleanse sterilization process. While there have been reports comparing outcomes of irradiated allografts to autografts as well as aseptic allografts, the functional outcomes using BTB grafts that have been chemically, non-thermally sterilized have not been reported in the literature. It should be noted that 'aseptic' processing does not necessarily mean that the tissue is free of viruses, bacteria, and/or spores. The possibility of contamination coming from the donor cannot be eliminated and could be inherent to the graft [4], which is why tissue banks attempt to clean with different chemical processes.

A number of clinical studies have been published $[13,15,19,22,32,35,37,38]$ which compared allografts and autografts in ACL reconstruction. A recent metaanalysis demonstrated no clinical difference when Level I studies were analysed [11]. This study attempted a standardized single bundle, isocentric, anatomical footprint ACL reconstruction for each surgical site to try and ensure consistency within the study.
These results show comparable outcomes between aseptically processed allografts and those that have been sterilized using the BioCleanse process. The importance of this lies in the reduction in the risk of disease transmission which has been documented [5]. Although appropriate donor screening and aseptic harvesting techniques can reduce the risk [17, 33], a method of sterilization that does not damage the structural integrity of the graft is essential. The BioCleanse process inactivates or removes sources of infectious disease transmission without compromising structural integrity of allograft bone and soft tissue [29, 34]. Validation tests of the process have indicated a sterility assurance level of $10^{-6}$ [18]. The FDA also states that a sterility assurance level of $10^{-6}$ is necessary for all devices unless there is substantial justification why this level cannot be achieved [43]. An important difference between BioCleanse and other sterilization processes is that BioCleanse does not use irradiation, ethylene oxide, or excessive heat, all of which may adversely impact the properties of the graft tissue [8-10, 26, 36, 41].

There are some limitations to this study. While it may be pointed out that the number of sites may affect reliability, previous literature has pointed to the high intertester reliability when using the KT-1000 [25], and that examiner experience can improve the precision and reliability when using multiple sites [31]. Considering the years of experience of the principal investigators, we expect that the reliability between sites would be high. Statistically, an improved power would make the results more certain. Although 67 patients were initially enrolled in this study, the loss to follow-up resulted in only 18 patients in the BioCleanse group and 10 in the aseptic group at 24 months, which reduced the statistical power in the study. The difference in group sizes had been anticipated in the initial statistical plan for an unbalanced design, yet the diminishing numbers did impact power. It should be noted that the loss of patients to follow-up did affect the power of the final statistical analysis, with the power of the KT analysis calculated to be 0.75 , while the power of the IKDC test was calculated to be 0.52 .

Also, although the same surgical technique and rehabilitation protocol were applied for all patients at all sites, the role of individual technique as well as adherence to rehabilitation guidelines can introduce variance in the results.

Lastly, while we had initially attempted to compare BioCleanse, aseptic, and gamma-irradiated allografts, extremely low enrolment in the gamma-irradiated arm prevented an adequate statistical comparison. This was due to a general shift away from irradiated allografts and was coupled with several patients who declined to participate in this study when they were informed they might receive an irradiated graft. 


\section{Conclusions}

All patients, whether receiving BioCleanse BTB allografts or aseptically processed BTB allografts, exhibited similar clinical outcomes. There were no complications, with only one revision required in each group. This short-term data shows that the BTB allografts processed through the BioCleanse process provide a viable option for ACL reconstruction while minimizing the risk of disease transmission.

Acknowledgments This study was funded by RTI Biologics, which processes the BioCleanse allografts. The funding consisted of provision of the knee arthrometers and compensation for the clinics' time spent in data collection and record keeping.

Conflict of interest Drs. Ciccotti, Higgins Shaffer have had no financial interest in the company during the last 5 years. Drs. Indelicato and Boyd are paid consultants of RTI Biologics. Dr. Vangsness has served as an expert witness on behalf of RTI Biologics. The authors have no conflict of interest in this study.

Open Access This article is distributed under the terms of the Creative Commons Attribution License which permits any use, distribution, and reproduction in any medium, provided the original author(s) and the source are credited.

\section{References}

1. Almqvist KF, Willaert P, De Brabandere S, Criel K, Verdonk R (2009) A long-term study of anterior cruciate ligament allograft reconstruction. Knee Surg Sports Traumatol Arthrosc 17(7):818 822

2. Baer GS, Harner CD (2007) Clinical outcomes of allograft versus autograft in anterior cruciate ligament reconstruction. Clin Sports Med 26(4):661-681

3. American Association of Tissue Banks (2006) Guidance document: current good tissue practice. American Association of Tissue Banks, McLean, Virginia. http://www.aatb.org/GuidanceDocument

4. CDC (2001) Septic arthritis following anterior cruciate ligament reconstruction using tendon allografts - Florida and Louisiana, 2000. MMWR Morb Mortal Wkly Rep 50(48):1081-1083

5. CDC (2003) Hepatitis C virus transmission from an antibodynegative organ and tissue donor-United States, 2000-2002. MMWR Morb Mortal Wkly Rep 52(13):273-274 276

6. Chang SK, Egami DK, Shaieb MD, Kan DM, Richardson AB (2003) Anterior cruciate ligament reconstruction: allograft versus autograft. Arthroscopy 19(5):453-462

7. Chehab EL, Flik KR, Vidal AF, Levinson M, Gallo RA, Altchek DW, Warren RF (2011) Anterior cruciate ligament reconstruction using achilles tendon allograft: an assessment of outcome for patients age 30 years and older. HSS J 7(1):44-51

8. Conrad BP, Rappe M, Horodyski M, Farmer KW, Indelicato PA (2012) The effect of sterilization on mechanical properties of soft tissue allografts. Cell Tissue Bank. doi:10.1007/s10561-0129340-2

9. Curran AR, Adams DJ, Gill JL, Steiner ME, Scheller AD (2004) The biomechanical effects of low-dose irradiation on bone-patellar tendon-bone allografts. Am J Sports Med 32(5):1131-1135

10. Fideler BM, Vangsness CT Jr, Lu B, Orlando C, Moore T (1995) Gamma irradiation: effects on biomechanical properties of human bone-patellar tendon-bone allografts. Am J Sports Med 23(5):643-646

11. Foster TE, Wolfe BL, Ryan S, Silvestri L, Kaye EK (2010) Does the graft source really matter in the outcome of patients undergoing anterior cruciate ligament reconstruction? An evaluation of autograft versus allograft reconstruction results: a systematic review. Am J Sports Med 38(1):189-199

12. Goldblatt JP, Fitzsimmons SE, Balk E, Richmond JC (2005) Reconstruction of the anterior cruciate ligament: meta-analysis of patellar tendon versus hamstring tendon autograft. Arthroscopy 21(7):791-803

13. Guo L, Yang L, Duan XJ, He R, Chen GX, Wang FY, Zhang Y (2012) Anterior cruciate ligament reconstruction with bone-patellar tendon-bone graft: comparison of autograft, fresh-frozen allograft, and gamma-irradiated allograft. Arthroscopy 28(2):211-217

14. Huber FE, Irrgang JJ, Harner C, Lephart S (1997) Intratester and intertester reliability of the KT-1000 arthrometer in the assessment of posterior laxity of the knee. Am J Sports Med 25(4):479-485

15. Lawhorn KW, Howell SM, Traina SM, Gottlieb JE, Meade TD, Freedberg HI (2012) The effect of graft tissue on anterior cruciate ligament outcomes: a multicenter, prospective, randomized controlled trial comparing autograft hamstrings with fresh-frozen anterior tibialis allograft. Arthroscopy 28(8):1079-1086

16. Leal-Blanquet J, Alentorn-Geli E, Tuneu J, Valenti JR, Maestro A (2011) Anterior cruciate ligament reconstruction: a multicenter prospective cohort study evaluating 3 different grafts using same bone drilling method. Clin J Sport Med 21(4):294-300

17. Marthy S, Richter M (1998) Human immunodeficiency virus activity in rib allografts. J Oral Maxillofac Surg 56(4):474-476

18. McAllister DR, Joyce MJ, Mann BJ, Vangsness CT Jr (2007) Allograft update: the current status of tissue regulation, procurement, processing, and sterilization. Am J Sports Med 35(12): $2148-2158$

19. Mehta VM, Mandala C, Foster D, Petsche TS (2010) Comparison of revision rates in bone-patella tendon-bone autograft and allograft anterior cruciate ligament reconstruction. Orthopedics 33(1): 12

20. Moller E, Weidenhielm L, Werner S (2009) Outcome and kneerelated quality of life after anterior cruciate ligament reconstruction: a long-term follow-up. Knee Surg Sports Traumatol Arthrosc 17(7):786-794

21. Mroz TE, Joyce MJ, Steinmetz MP, Lieberman IH, Wang JC (2008) Musculoskeletal allograft risks and recalls in the United States. J Am Acad Orthop Surg 16(10):559-565

22. Mroz TE, Lin EL, Summit MC, Bianchi JR, Keesling JE Jr, Roberts M, Vangsness CT Jr, Wang JC (2006) Biomechanical analysis of allograft bone treated with a novel tissue sterilization process. Spine J 6(1):34-39

23. Nakata K, Shino K, Horibe S, Tanaka Y, Toritsuka Y, Nakamura N, Koyanagi M, Yoshikawa H (2008) Arthroscopic anterior cruciate ligament reconstruction using fresh-frozen bone plugfree allogeneic tendons: 10-year follow-up. Arthroscopy 24(3): 285-291

24. Poehling GG, Curl WW, Lee CA, Ginn TA, Rushing JT, Naughton MJ, Holden MB, Martin DF, Smith BP (2005) Analysis of outcomes of anterior cruciate ligament repair with 5-year follow-up: allograft versus autograft. Arthroscopy 21(7):774-785

25. Queale WS, Snyder-Mackler L, Handling KA, Richards JG (1994) Instrumented examination of knee laxity in patients with anterior cruciate deficiency: a comparison of the KT-2000, knee signature system, and genucom. J Orthop Sports Phys Ther 19(6):345-351

26. Rappe M, Horodyski M, Meister K, Indelicato PA (2007) Nonirradiated versus irradiated achilles allograft: in vivo failure comparison. Am J Sports Med 35(10):1653-1658 
27. Reid A, Birmingham TB, Stratford PW, Alcock GK, Giffin JR (2007) Hop testing provides a reliable and valid outcome measure during rehabilitation after anterior cruciate ligament reconstruction. Phys Ther 87(3):337-349

28. Robnett NJ, Riddle DL, Kues JM (1995) Intertester reliability of measurements obtained with the KT-1000 on patients with reconstructed anterior cruciate ligaments. J Orthop Sports Phys Ther 21(2):113-119

29. Schimizzi A, Wedemeyer M, Odell T, Thomas W, Mahar AT, Pedowitz R (2007) Effects of a novel sterilization process on soft tissue mechanical properties for anterior cruciate ligament allografts. Am J Sports Med 35(4):612-616

30. Schwartz HE, Matava MJ, Proch FS, Butler CA, Ratcliffe A, Levy M, Butler DL (2006) The effect of gamma irradiation on anterior cruciate ligament allograft biomechanical and biochemical properties in the caprine model at time zero and at 6 months after surgery. Am J Sports Med 34(11):1747-1755

31. Shultz SJ, Nguyen AD, Windley TC, Kulas AS, Botic TL, Beynnon BD (2006) Intratester and intertester reliability of clinical measures of lower extremity anatomic characteristics: implications for multicenter studies. Clin J Sport Med 16(2):155-161

32. Singhal MC, Gardiner JR, Johnson DL (2007) Failure of primary anterior cruciate ligament surgery using anterior tibialis allograft. Arthroscopy 23(5):469-475

33. Suarez LS, Richmond JC (2007) Overview of procurement, processing, and sterilization of soft tissue allografts for sports medicine. Sports Med Arthrosc 15(3):106-113

34. Sun K, Tang JW, Xu Q, Liu XY, Zhou LG, Hao YQ, Wang L, Sun YJ (2004) A prospective study of the anterior cruciate ligament reconstruction: allograft versus autograft. Zhonghua Wai Ke Za Zhi 42(16):989-992
35. Sun K, Tian S, Zhang J, Xia C, Zhang C, Yu T (2009) Anterior cruciate ligament reconstruction with BPTB autograft, irradiated versus non-irradiated allograft: a prospective randomized clinical study. Knee Surg Sports Traumatol Arthrosc 17(5):464-474

36. Sun K, Tian SQ, Zhang JH, Xia CS, Zhang CL, Yu TB (2009) ACL reconstruction with BPTB autograft and irradiated fresh frozen allograft. J Zhejiang Univ Sci B 10(4):306-316

37. Sun K, Tian SQ, Zhang JH, Xia CS, Zhang CL, Yu TB (2009) Anterior cruciate ligament reconstruction with bone-patellar tendon-bone autograft versus allograft. Arthroscopy 25(7):750759

38. Sun K, Zhang J, Wang Y, Zhang C, Xia C, Yu T, Tian S (2012) A prospective randomized comparison of irradiated and non-irradiated hamstring tendon allograft for ACL reconstruction. Knee Surg Sports Traumatol Arthrosc 20(1):187-194

39. Vaishnav S, Vangsness CT Jr, Dellamaggiora R (2009) New techniques in allograft tissue processing. Clin Sports Med 28(1): $127-141$

40. Vangness CT (1996) Soft tissue for allograft reconstruction of the human knee. Am J Sports Med 24:230-234

41. Vangsness CT Jr, Dellamaggiora RD (2009) Current safety sterilization and tissue banking issues for soft tissue allografts. Clin Sports Med 28(2):183-189 vii

42. Vangsness CT Jr, Garcia IA, Mills CR, Kainer MA, Roberts MR, Moore TM (2003) Allograft transplantation in the knee: tissue regulation, procurement, processing, and sterilization. Am J Sports Med 31(3):474-481

43. Vangsness CT Jr, Wagner PP, Moore TM, Roberts MR (2006) Overview of safety issues concerning the preparation and processing of soft-tissue allografts. Arthroscopy 22(12):1351-1358 